\title{
THE DILEMMAS OF DIGITAL METHODOLOGIES: LEARNING FROM WORK ON YOUNG DIGITAL
}

\author{
Susan Elsley, Michael Gallagher, and E. Kay M. Tisdall
}

\begin{abstract}
This article explores common dilemmas facing researchers and practitioners who wish to use digital media in research with children and young people. The article explores both cultural-social-economic and material approaches to digital media. These draw attention to five areas, explored in the article, which raise particular dilemmas and opportunities: networked mobility; interoperability and convergence; corporate involvement; confidentiality, anonymity and privacy; and intellectual property and moral rights. When involving children and young people through digital media, the boundaries between online and offline worlds are increasingly blurred, raising practical and ethical dilemmas. The article concludes that research with children and young people needs to take account of the socio-cultural norms in using digital media and that the tenets of ethical research still apply.
\end{abstract}

Keywords: digital, digital media, children, young people, networked, confidentiality, privacy, intellectual property rights

Acknowledgements: The Economic and Social Research Council's Digital Demonstrator Programme provided funding to create Young Digital, in the project 'Supporting the use of digital media in research with children and young people’ (ES/J009814/1).

Susan Elsley (the corresponding author) is an independent researcher on children and young people and a research associate of the Centre for Research on Families and Relationships at the University of Edinburgh, 23 Buccleuch Place, Edinburgh, EH8 9LN, UK. E-mail: susan@susanelsley.com

Michael Gallagher is Senior Lecturer in the Early Years and Childhood Studies, Faculty of Education, Manchester Metropolitan University, Birley Building, 53 Bonsall Street, Manchester M15 6GX.

E-mail: m.gallagher@mmu.ac.uk

E. Kay M. Tisdall is Professor of Childhood Policy and Co-Director of the Centre for Research on Families and Relationships, at the University of Edinburgh, SPSS CMB, 15A George Square, Edinburgh EH8 9LD, UK.

E-mail: k.tisdall@ed.ac.uk 
Digital media are now an integral part of everyday life for many people. Boundaries between online and offline worlds are increasingly difficult to delineate, with digital media tools now used as part of routine activities and mobile technology no longer restricting the geography of usage, with some provisos of access, inclusion, and location.

As researchers with longstanding interests in both research with children and young people ${ }^{1}$ and experimentation with digital media, we wanted to explore the potential of using digital media in research. The popularity of these media amongst many children and young people, matched with the commitment of childhood studies researchers to gather data in ways that are engaging and meaningful to participants, were significant incentives. To support these interests, since 2010 we have been running a course on using digital media in research with children and young people at the Centre for Research on Families and Relationships, University of Edinburgh, for researchers from the higher education, public, and non-governmental sectors. The training has provided rich opportunities for collaborative learning and exploration about the benefits and challenges of using digital media in research. That learning informs this article.

At the outset of developing our course on using digital media in research, few materials were available to childhood studies researchers who wanted to use digital media and explore their potential. Since then, on a year-by-year basis, we have seen a growth in available resources and significant changes in what participants bring to the course, through their own use of digital media and their experimentation in research with children and young people.

In order to meet a need for curated resources, we received funding from the Economic Social Research Council (ESRC) Digital Demonstrator Programme to develop a web resource in 2011. This initiative, Young Digital (available at http://www.youngdigital.net/), was launched in early 2013 and draws on resources from academic research and learning from other areas such as children and young people's participation, reflecting wider experience of using digital media relevant for research.

This article explores some common dilemmas and debates that have arisen in our work and draws on an increasing body of knowledge on using digital media in research. It draws attention to the evolving use of digital media by children and young people and explores issues which have resonance for our research activities. Five areas are explored in this article: networked mobility; interoperability and convergence; corporate involvement; confidentiality, anonymity and privacy; and intellectual property and moral rights.

\footnotetext{
${ }^{1}$ This article generally uses the phrase “children and young people”, following young people’s typical preference to be referred to as the latter in the United Kingdom. Broadly, "children and young people” refers to children up to the age of 18, following the definition within the United Nations Convention on the Rights of the Child.
} 
The article considers in what ways these reflect and continue issues raised by traditional offline methods for children and young people's research, and in what ways they are reformulated or raise new issues when various types of digital media are being used. Finally, we suggest areas that researchers might consider when undertaking research with children and young people.

\section{Defining and Theorizing Digital Media}

Throughout this article, we use the term "digital media”. However, this term is troublesome to define. It encompasses a vast spread of technologies: everything from traffic lights to travel clocks, from elevators to engine management systems, from mobile phones to military drones (Kitchin \& Dodge, 2011). Academic researchers have a long tradition of using digital tools for learning, analysis, dissemination, and knowledge exchange. Social research, for example, routinely involves digital technologies, such as analytical software packages SPSS and NVIVO, and more general-purpose tools such as word processing, spreadsheets, and databases. These are not, however, the kinds of digital media with which we are concerned in this article.

Another challenge in defining digital media is their continued evolution, emerging from longer histories. Contrary to popular belief, digital media are not phenomena arising only in the last two decades. For example, the MP3 format, now widely used for music distribution, can be traced back to developments in psychoacoustic research and the telephone industry from the early 1900s (Sterne, 2012). Likewise, Meikle and Young (2012, p. 3) point out that "The Internet which underpins the web is more than forty years old ... The history of the mobile phone might be traced back as far as Marconi or even Morse". They conclude that "the digitization of media content is now so pervasive and so firmly established that the term [digital media] is unhelpful as a general label” (p. 3). In our work, however, we have retained the term digital media as an inclusive category, with an emphasis on the resources and technological products that children and young people are currently using to exchange information via the Internet, such as mobile networked devices, social media, and other Web 2.0 technologies.

The pervasiveness of digital media applies manifestly to the minority world ${ }^{2}$ but also to the majority world. In 2011, for example, Africa was the second largest market for mobile connections after Asia, with year on increases of 30\% during the previous decade (GSMA-Kearney, 2011). Although these figures suggest that digital media are increasingly widespread and global, inequalities remain in both the minority and majority worlds in terms of access, inclusion, and availability of technology. In a European study, for example, connectivity, cost (especially for younger children), and access to wireless connections affected children and young people's access to the Internet via mobiles (Masheroni \& Ólafsson, 2013).

A recurring theme throughout this article is the blurring of boundaries between online and offline worlds. In the discourses surrounding the popularization of the

\footnotetext{
${ }^{2}$ The terms "majority world" and "minority world" refer to what has traditionally been known as "the third world" and "the first world" or more recently as "the Global South" and "the Global North". This acknowledges that the majority of population, poverty, land mass, and lifestyles is located in the former - in Africa, Asia and Latin America - and thus seeks to shift the balance of our world views that frequently privilege "western” and "northern” populations and issues (Punch 2003).
} 
Internet during the 1990s, a distinction was commonly made between online and offline spaces, expressed in concepts such as virtual space and cyberspace (Slater, 2002). This distinction is problematic, since how such boundaries are perceived, enacted, or dissolved will vary between different assemblages of technologies, places, and people. As digital media have become ubiquitous in everyday life, the distinction has been undermined by various factors: the increasing mobility of new technologies; their aggressive marketing as lifestyle accessories; the sheer "diversity of software and hardware" (Slater, 2002, p. 534) of which the Internet is comprised, undermining any sense of the online world as a single coherent entity; and related changing practices of media use. This is not to argue that divisions between online and offline spaces are no longer being made, but rather that such divisions are increasingly porous, uncertain, and contested. Of particular relevance for this article, our research and teaching experiences suggest that children and young people who have never known a world without ubiquitous digital media tend to perceive the distinctions between online and offline as more fluid and less sharply drawn than many adult researchers. This is a broad generalization with many exceptions, but we have found it to be particularly true of those older adult researchers who have substantial experience of the pre-Internet era, and whose use of online networked media outside of a work context is limited. As we will discuss in subsequent sections, these differing conceptions of the online-offline divide have significant implications for using digital media in research.

In addressing questions about the characteristics of digital media, two approaches suggest themselves. The first is cultural-social-economic, examining the discourses, practices, social, and economic relationships within which digital technologies are embedded. This could be described an outward-facing analysis, examining the wider context surrounding digital media. It might involve enquiries into how children and young people use mobile devices or navigate the public spaces of social media (e.g., boyd, 2007), or critical interrogation of how digital technologies are bound up with wider political-economic structures of capitalism, neo-liberal consumerism, and globalization (Dijck, 2013). The second approach is a more materialist analysis of media, exemplified by media archaeology (e.g., Huhtamo \& Parikka, 2011) and certain strains of media ecology (e.g., Fuller, 2007). Here analysis tends to be more inward-looking, examining digital media themselves, treating them not only as socially embedded tools but as machinic entities in their own right, radically non-human, non-semantic and non-discursive, and with the potential to interact in ways that exceed their designers' intentions. In directing attention towards media's technical functioning, a materialist approach can reveal what machines bring to research, and also help to counter the implicit humanism that often characterizes childhood studies (see Prout, 2005). Combining these two approaches, boyd (2008) writes of the properties and dynamics of "networked publics" that make digital media practices different from other unmediated publics: the properties of persistence, searchability, replicability, and scalability; and the dynamics of invisible audiences, collapsed contexts - "the lack of spatial, social, and temporal boundaries makes it difficult to maintain distinct social contexts” (p. 34) - and the blurring of private and public.

Both cultural-social-economic and materialist approaches offer useful and complementary insights for reflexive thinking about the use of digital media in research. In the following sections, we use them to highlight several specific features, 
issues, and dilemmas relating to the mobile, social, and audio-visual digital media with which we are concerned here. As social researchers, cultural-social-economic observations predominate in our account, but with the material and technical aspects of digital media also coming to the fore at points.

\section{Children and Young People's Digital Media Use}

Digital media offers new opportunities for research. Edwards, Housley, Williams, Sloan, and Williams (2013) suggest that current thinking about the contribution of Web 2.0 technologies to research can be categorized in three ways: it can provide a "surrogate" for existing traditional methods; it can "re-orientate" research so that it considers new populations and data; finally it can "augment" traditional research (p. 245). For childhood studies researchers seeking innovative ways of engaging children and young people, using digital media can be attractive for these methodological reasons. But it is also attractive because children and young people's use of digital media has grown so rapidly over the last decade, indicating wide interest in these technologies. Recent figures from Ofcom, the U.K.'s independent regulator for the communication industries, show, for example, that children and young people's access to smart phones and tablet computers in the U.K. has increased year on year (Ofcom, 2013). In 2012, the use of tablet computers by children and young people between the ages of 5 to 15 years had tripled from the previous year (Ofcom, 2013); 62\% of young people between 12 and 15 years had smart phones, with these devices the most popular for accessing social networking sites (Ofcom, 2013). These growing figures are reflected elsewhere, with 53\% of children and young people in a study of six European countries likely to own or access the Internet every day using a smartphone (Masheroni \& Ólafsson, 2013). Children and young people are increasingly digitally well connected.

Children and young people are often considered "early adopters" of social networking media; they are often also "early adapters". So the popularity of the social network Myspace, once a favorite of children and young people, has declined. The dominance of Facebook is now being encroached upon by newer applications, with Ofcom reporting more diverse use of social networking sites amongst children and young people (Ofcom, 2013). Most children and young people are still using Facebook, according to research undertaken in the United States, but they are concerned about the "adult presence" and oversharing of information on the platform (Madden et al., 2013) and are using other social networking tools to circumvent possible adult intrusion. As of 2014, new applications such as WhatsApp, Snapchat (launched in 2011) and Vine (launched in 2013) are being used by children and young people in greater numbers. Being aware of children and young people's evolving patterns of media use can inform the work of childhood studies researchers, providing them with insights about what is appropriate for research activities.

It is a mistake, however, to take these trends as evidence that today's children and young people are "digital natives”, not only because that concept lacks an empirical basis (Hargittai, 2010; Helsper \& Eynon, 2009; Selwyn, 2009), but because, as already highlighted, "the digital" is too amorphous and unstable to pin down. There is no reason to suppose that children and young people who are familiar with, say, social media will be capable of programming software or working with big data, nor that their familiarity with current technologies will automatically give them an 
intuitive grasp of new technologies in the future. The notion that children and young people are uber-confident digital citizens, with skills that can surpass those of adults, should therefore be treated with caution. This suggests that researchers should be careful about the assumptions they make about children and young people's digital media skills. These might be limited to routine everyday use rather than based on indepth understanding of all aspects of digital media.

\section{Networked Mobility}

The rise of mobile networked devices is changing the geography of digital media. Children and young people are using digital media in diverse spaces, including homes, schools, outdoor spaces, on transport systems, in public institutions such as libraries and museums, and at gatherings such as gigs and music festivals. This affords possibilities for data collection to become more mobile and peripatetic, happening wherever children and young people happen to be (Plowman \& Stevenson, 2012). The mobility of smartphones has some continuity with other portable media such as the Walkman and portable MP3 player, but a crucial distinction is the capacity of smartphones to enable the creation and sharing of data via the Internet whilst on the move, out-and-about, shuttling information between disparate spaces.

Thinking through the materiality of these technologies, one key issue is that of bandwidth. At the time of writing, for example, mobile data transfer is generally slower than with wired connections. Economies of compression thus trump quality and fidelity, a principle evident in everything from the grainy texture of online videos to the 140-character limit of SMS text messages and Tweets. For researchers used to lengthy surveys, in-depth interviews, and richly detailed data, a key challenge here is to find ways of working with more minimal nuggets of information.

Taking a more social-cultural perspective, the geographically locative capacities of networked mobile devices have significant implications for research, both in terms of methods and ethics. Mobile devices now commonly interface with what has become known as the "geoweb", using GPS technology for navigation, mapping, the locational tagging of media (geotagging), locative augmented reality, and other geographical functions. These technologies are deeply ambivalent. They are powerful tools for the surveillance of civil society by states and corporations, but also afford opportunities for counter-hegemonic and activist practices, such as using satellite imagery to identify geopolitical installations (Perkins \& Dodge, 2009). Researchers working with such technologies can use them to track participants' movements, pinpoint the spaces in which certain responses were made and map research data, thereby extending traditional quantitative epistemologies, with their capacity to turn social action into fixed, calculable knowledge. Locative media can also be used to provide interactive, participatory, collaborative, and creative ways of researching people's relationships with spaces and places, such as through locationbased storytelling (e.g., Miskelly, Cater, Fleuriot, Williams, \& Wood, 2005).

Geolocation is an area in which digital media has produced novel datagenerating capabilities quite unlike anything that is possible with traditional offline research methods. Careful reflexivity is therefore needed around the ethics of using these media, particularly concerning anonymity and privacy. Elwood and Leszczynski (2011) argue that geolocated media reconfigure privacy in a distinctive way. Unlike 
the abstracted attributes of transactional "big" data, geolocated media provide more immediate representations of personal identities, such as the photorealistic visual images of pedestrians and private homes in Google's Street View. Such data have a particular kind of truth value, purporting to show certain individuals at a given location and time. It is this immediacy and directness, Elwood and Leszczynski (2013) suggest, that has influenced heated debates about privacy in relation to the geoweb. All of this suggests that, in research with children and young people on sensitive or difficult topics, or where data collection is taking place in children and young people's private spaces such as their homes, there may be good ethical reasons not to track their locations. Some devices and platforms register location by default, so researchers concerned about anonymity and privacy may need to be proactive in disabling such features.

\section{Interoperability and Convergence}

Mobile, social, and audio-visual digital media are increasingly designed to integrate, interact, and exchange data. Older media forms tend to be more limited in this respect. The materiality of information printed in a traditional printed book, for example, means that it is not easily transferred out of that format and into a different context, whereas digital formats are highly interchangeable, allowing both for easy cut-and-pasting between files, and for data to float more freely between multiple material-technological assemblages. Digital text, images, and audio can propagate across a wide variety of devices, easily copied and shared via social media channels. For example, consider embedded media, whereby content hosted by one social media service can be placed within other websites: photos hosted on Flickr can be placed within Facebook pages and Tumblr posts, or Tweets embedded in a blog. More generally, some commentators have identified a trend towards what has been termed media convergence or remediation, whereby networked digital media precipitate the combination and reworking of media forms (Bolter \& Grusin, 1999; Jenkins, 2006; Meikle \& Young, 2012). One example is the blurring of lines between television and the Internet through catch-up and on-demand services and video sharing platforms such as YouTube.

Harnessing interoperability and convergence for research will involve making technical decisions to use open-ended platforms, standards, and formats that have wide compatibility. This can make for the spontaneous criss-crossing, reworking, and hybridization of data, extending older practices such as collage, remixing, and sampling. Encouraging participants to share data may result in a lateral movement of proliferation, even sometimes contagion - things "going viral" - though equally there may be a deflating lack of interest. Media interoperability offers lively, emergent potentials, particularly for dissemination, but can also undermine control over research and the contexts within which it is presented. The casual promiscuity of the World Wide Web can be a shock for those more used to keeping their findings behind firewalls or in filing cabinets.

One cultural-social effect of media convergence relates again to the reworking of the distinction between private and public. Spheres of life that have traditionally tended to be kept separate offline, such as work, family, and friends, now increasingly converge through online media. Participants in our digital media courses have expressed anxieties about managing personal and professional boundaries on social 
media, reflecting a wider sense that public-private divisions in online practices are still evolving, and have yet to settle into accepted norms. The implications of this for research are not fundamentally new. There are precedents in negotiating personalprofessional boundaries in ethnographic research, for example (Everhart, 1977; Blackman, 2007), and the core issues remain similar. However, digital media add an additional level of complexity to how these issues play out in practice. The convergence and anonymity of networked media, combined with the emerging and changing social conventions in using these media, have produced a situation where many young people use the Internet to negotiate and experiment with sexuality, friendships, and family relationships. This involves young people sharing intimate personal information about themselves and others, including through photos and videos. In some cases such material may constitute valuable data, but there is also a danger of research becoming unintentionally invasive or voyeuristic, and of researchers and young people having interactions that feel uncomfortable or inappropriate - either for the researchers, the young people, or both.

In thinking through these issues, some questions to consider include: Will researchers use an existing personal social media profile or set up a separate one for research? How will researchers respond to Facebook "friend" requests from research participants? Will researchers give research participants a mobile phone number for exchanging texts? Will researchers take their numbers? How much personal information are researchers happy to share? If children and young people send messages or friend requests to researchers' personal social media profiles, how will researchers respond? How will researchers deal with sociable online interactions such as off-topic chat and flirting? Considering these issues at the planning stage, and drawing on digital media protocols from other professionals working with children and young people, may help researchers to be better prepared for some of the consequences of using digital media in their work.

\section{Corporate Involvement}

The corporate politics and economics of digital media is another culturalsocial issue with major implications for research practice. At present, a small number of multinational companies and conglomerates dominate the market in digital devices and services. The control of media by public and private corporations is nothing new, but the current configuration is distinctive in the unprecedented quantities of data now harvested from users. Web 2.0 media:

are based on a model where profit margins are maximized the more users join the network (which is why access is free or extremely low cost), and the more demographic data those users provide so that advertising can be targeted at them. In other words, if we are not paying for a product, we are the product. (Mejias, 2013, p. 33)

For example, Facebook's advertising web pages boast that its user-generated data can enable companies to target their products based on the location, sex, age, likes and interests, relationship status, workplace, or education of Facebook members. There is, then, a kind of Faustian pact whereby using digital media services to generate research data also involves allowing digital media companies to generate big data for their own commercial purposes. Internet interactivity cuts both ways. 
Tricky ethical questions arise here about how to manage digital research data generated by participants or young people as co-researchers, particularly given the profit-driven motives of the companies in question. The tax avoidance strategies of Google, for example, sit uneasily with the publicly funded, social justice orientated nature of much research in childhood studies. Dijck (2013) argues that the culture of exchange in social media is based on neo-liberal economic principles, and that the calls of large social media corporations for "more transparency and openness, for maximum sharing and frictionless traffic, are entrenched in a neoliberal political agenda often advocating a downsizing of the public sector” (p. 21). A materialist analysis of digital media also points towards economic and environmental injustices. Mejias (2013) highlights a few examples: the appalling labour conditions through which the rare earth minerals required for making digital devices are extracted in Congolese mines; the high rate of employee suicide at Foxconn's factories in China, where Apple products are assembled; the toxic environmental and health effects of electronic waste.

Against this background, as researchers we may wish to consider the extent to which we want to allow our activities and those of our participants to be co-opted into generating surplus value for multinational corporations. Beyond a simple binary decision about whether or not to use digital media, Mejias (2013) observes that a range of decisions are possible such as:

a refusal to do business with certain companies, or a rejection of the premise that we must upload our content to the network with the most users. It might actualize itself as the struggle to get corporations to change their terms of service; or the promotion of open-source, open-content, or peer to peer alternatives.... Perhaps the movement to disrupt digital networks will be what the slow food movement is to fast food: an opportunity to stop and question the meaning of progress. (pp.158-159)

These considerations can be seen within the wider context of the politics and ethics of childhood studies research.

\section{Confidentiality, Anonymity, and Privacy}

One of the most significant cultural-social areas of concern about digital media and research is a series of interconnected issues around confidentiality, anonymity, and privacy. These issues are well known in traditional offline research, where childhood studies researchers discuss, for example, the necessity of ensuring confidentiality and anonymity in the research context, while limiting this when a child or young person is unsafe or at risk (Alderson \& Morrow, 2011). But such ethical issues raise additional challenges in a digital research context. Researchers not only have to ensure secure and appropriate approaches in a research environment, but also have to navigate systems which may be outside their control: for example, using commercial tools that are not ultimately secure, and that may therefore breach participants' privacy. Even supposedly secure services can experience leaks, cyberattacks, and data theft. Anonymity is difficult to maintain when using Facebook or other publicly accessible social networking media. Confidentiality can be compromised if data are inappropriately or inadvertently shared by peers in or outside 
the research context. A young person at risk of harm (e.g., vulnerable because of bullying or other forms of violence) could be unsafe if his or her identity is known outside of the researcher/participant relationship. These broad ethical issues are of concern to researchers offline as well as online. However, the commercial and public nature of digital media adds a layer of additional complexity for the online researcher.

Children and young people may have particular understandings of privacy and anonymity in their interactions on the Internet that are different from adults' understandings. Barnes (2006) describes the "privacy paradox" where adults talk of being concerned about their privacy but at the same time have detailed personal information on social network profiles. Children and young people may similarly be unaware of the public nature of their identities online. They may not be concerned about or aware of the longevity of their digital futures and the legacy of their childhoods and young adulthoods online. Or they may be privileging other advantages, such as establishing and developing relationships, over these concerns. For the researcher, this may mean establishing different practices among children and young people for the research project, contrary to their customary use.

So what do these issues mean for research with children and young people? Is it ethical to analyze publicly available digital media like YouTube, Twitter, or Facebook pages without privacy settings? It is being done already. If something is interactive, how do we deal with the blurring of privacy and public information, such as photographs being sent from a young person's mobile without the consent of a person being photographed? It can help to consider, at the planning stage of a research project, how researchers will negotiate these challenges. Are there spaces that researchers want to encourage children and young people to use for interacting with the research project? Or spaces that researchers want to advise them to avoid using, for reasons of safety, privacy, or comfort for example? Such decisions will need to be informed by careful consideration of the topic's sensitivity and the possible risks and benefits to participants.

Practical strategies to address some of these challenges include the use of encryption software, password protection, secure servers, exploring privacy settings, encouraging children and young people not to share certain kinds of information online, or investigating the possibilities of using digital media offline, such as through non-networked audio, video, and photography activities. Childhood studies researchers can take advantage of standard protocols around Internet safety for children and young people, including specific redress mechanisms should a child or young person feel the research has invaded his or her privacy.

But it may also be necessary for researchers to tolerate a degree of uncertainty, a difficult challenge for childhood studies' researchers who are committed to ensuring ethical practice. Digital media, their patterns of use and the discourses surrounding them continue to evolve rapidly, requiring an attitude that is open to improvisation, experimentation, and learning through trial and error, although this may not be possible when trying to gain formal ethical approval for research. It also might be problematic in working with other professionals, such as teachers or social workers, who have responsibilities for children and young people and are working within their institutional guidelines around digital media. 


\section{Intellectual Property and Moral Rights}

Intellectual property rights (IPR) is the final cultural-social-economic issue discussed in this article. Whilst IPR affects all research, when using digital media in research with children and young people, IPR gives rise to particular ethical and practical dilemmas. IPR, like design rights or copyright, legally sit within the “property” paradigm (see MacQueen, Waelde, \& Laurie, 2007; Ng, 2009/10). Thus the rights-holder has the right to control the use, possession, or other types of interference with his or her property. As property, the rights-holder can transfer, hire, bequeath, sell it and more. Ownership then becomes a critical issue and one with potential economic implications. Copyright is a form of intellectual property but is only offered to certain works, which must be "original" and tangible (so ideas are not covered but their tangible expression is likely to be; see JISCdigitalmedia for an accessible summary of U.K. law). Originality, as well as who has copyright ownership, thus become key questions. Authors may have moral rights, whether or not they have IPR, to have their authorship acknowledged, to object to false attribution, and to not have the work subjected to "derogatory treatment" (Copyright, Designs and Patents Act 1998, applying to the United Kingdom). Moral rights cannot be transferred but they can be waived. Authorship, alongside ownership, then becomes another issue.

There are counter ideas of authorship, ownership, and originality, however. Creative Commons has created a "middle ground", deliberately set up in 2002 to establish norms different from standard law and practice. A range of Creative Commons licenses allow for copyright to be retained but work to be used without permission and without payment (Kim, 2008). This is a useful way of dealing with, for example, the co-creation of wikis, open-source software and certain creative and artistic endeavours in which less importance is attached to the distinction between the passive consumer and the creative author; instead, replication and remixing can be seen as increasing status and reach (Kim, 2008; Ng 2009/10) or rendering authorship irrelevant (James et al., 2009). Rather than seeing creativity as an individual endeavour resulting in an outcome that can be owned and thus sold, Creative Commons implicitly reflects the notion of creativity as a process, as essentially participatory (Biggs \& Travlou, 2012). This parallels the hopeful aspiration that, despite the dominant online presence of multinational corporations (Dijck, 2013), the Internet can still create a more open and democratic culture, with free flows of information (see Buckingham, 2007). Certain of these norms mirror more traditional ideas and legal frameworks, while others run counter to them. At least three dilemmas then arise for research with children and young people.

First, by using digital media, researchers are seeking to tap into media that are enjoyed by and familiar to children and young people - ones that children and young people likely use at home rather than school, in their leisure time rather than for work (James et al., 2009). But children and young people's social-cultural norms when using these media - norms such as copying, changing, or transferring media - may not be legal or may go against (adult) researchers' own institutional and social norms, such as respecting copyright and seeking formal permission for the re-use of material.

Second, social science research has tended to privilege the (adult) researcher as author and to offer - but often in fact require - research participants' anonymity, 
which is seen as protective to the participants individually (see discussion in Gallagher, 2009). Counter-arguments have been made in offline research: for example, when children and young people are researchers in their own right (see Thomas, 2014); in dissemination activities involving children and young people (see Tisdall, 2005); and in recognizing the artist and creator, as arts-based and creative methods remain popular with children and young people (Tisdall, Davis, \& Gallagher, 2009). The co-production (from fieldwork to analysis) offered by Web 2.0 platforms highlights the problematic default positions of social science research in relation to authorship. (Adult) researchers can be accused of being exploitative and extractive, "profiting” from research participants by not publicly acknowledging their authorship and ownership, just as commercial companies are criticized for profiting from the coproduction of young gamers on their platforms (James et al., 2009).

Third, the use of commercial platforms raises particular issues for ownership and copyright. For example, the small print of "terms and conditions" as you sign up to use a particular platform may well waive or transfer certain of your moral or property rights (e.g., see Facebook). Thus, if a researcher encourages and uses a particular platform, they and their research participants may not legally retain their rights.

The lens of intellectual property rights, and the debates about them within digital media, bring into focus dilemmas about research methods, authorship and ownership, and participation. These are both offline and online dilemmas that encourage knowledge of the legal jurisdictions and frameworks, a weighing up of harms, benefits, and risks, and honest and reflexive engagement with all involved in research to determine how to proceed.

\section{Conclusion: Implications for Research with Children and Young People}

Our training courses, our work on the Young Digital resource, and co-learning with other researchers, have flagged up practical and ethical dilemmas about using digital media in research. Concerns about these issues can deter researchers. However, the possibilities of using digital media are difficult to ignore in a world where the boundaries between online and offline worlds are increasingly blurred and irrelevant, and where children and young people, like many adults, are routine users of digital media, regarding them as part of their everyday lives.

The use of digital media in research is not, after all, novel. Most researchers are already digitally connected. However, researchers may not always be comfortable using digital media as research tools with children and young people because of the complexity of ethical, technological, and practical issues that confront them. As a result, digital media may be used for discrete purposes, such as analysis, communication, dissemination, and knowledge exchange, rather than being deployed fully as research methodologies involving children and young people as participants or as co-researchers. These limitations are likely to diminish as familiarity with using digital media enables researchers to increase their own competencies and explore the ethical issues. In order to do this, researchers need opportunities to reflect critically on using digital media in their work with children and young people. 
Many issues that are central to childhood studies' research and digital media are replicated in wider societal discussions. In all of these, there are concerns about equitable access for all children and young people, the challenges in using a variety of digital media, and the dilemmas in ensuring that the use of digital media is safe, private when we want it to be, and an area of our lives over which we can have control (Lobe, Livingstone, Ólafsson, \& Simoes, 2008; Alderson \& Morrow, 2011). Researchers need to be attentive to these wider debates and explore the implications for their own research practice.

The tenets of ethical research still apply in digital contexts. These ethical approaches may require some additional considerations such as: how to ensure confidentiality and anonymity in digital spaces; how to use commercial media, which may have implications for privacy, ownership, and inclusion; and how to respond to concerns about inappropriate use of data now or in the future. These areas need to be explored by adult researchers with children and young people as part of the planning and development of research, throughout the research process and in postdissemination reflections.

These are issues to be wrestled with, and we see the use of digital media as emergent spaces for researchers. In five years time, we anticipate that digital media use by children and young people (and adults) will have developed further with new trends emerging. The ethical dilemmas that we have discussed are likely to have evolved in line with personal, societal, commercial, and governmental responses to these core issues. On the other hand, these dilemmas may remain constant through all the digital changes that will occur, requiring researchers to be vigilant in their interrogation of how and when to use digital media. This means that, as childhood studies researchers, we need to be competent users rather than strangers to digital media, attentive to changing norms and their ethical implications. We need to interrogate critically our use of digital media and be alert, principled, proactive, and pragmatic in responding to the challenges that arise. Taking these into account, we can then develop our research capacities, utilizing digital media in ways which are current and appropriate for research with children and young people. 
International Journal of Child, Youth, and Family Studies (2014): 5(4.1) 702-717

\section{References}

Alderson, P., \& Morrow, V. (2011). The ethics of research with children and young people. London: Sage. http://dx.doi.org/10.4135/9781446268377

Barnes, S. B. (2006). A privacy paradox: Social networking in the United States. Retrieved from http://firstmonday.org/ojs/index.php/fm/article/view/1394/1312

Biggs, S., \& Travlou, P. (2012). Distributed authorship and creative communities. Dichtung Digital, 41. Retrieved from http://www.dichtungdigital.de/en/journal/archiv/?issue=41

Blackman, S. J. (2007). 'Hidden ethnography’: Crossing emotional borders in qualitative accounts of young people's lives. Sociology, 41(4), 699-716.

Bolter, J. D., \& Grusin, R. A. (1999). Remediation: Understanding new media. Cambridge, MA \& London: MIT Press.

boyd, d. (2007). Why youth (heart) social network sites: The role of networked publics in teenage social life. In D. Buckingham (Ed.), MacArthur Foundation series on digital learning - Youth, identity, and digital media volume (pp. 119-142). Cambridge, MA: MIT Press.

boyd, d. (2008). Taken out of context: American teen sociality in networked public. Doctoral dissertation, University of California, Berkeley, Retrieved from http://www.danah.org/papers/TakenOutOfContext.pdf

Buckingham, D. (2007) Beyond technology: Children's learning in the age of digital culture. Cambridge, UK: Polity Press.

Dijck, J. v. (2013). The culture of connectivity: A critical history of social media. Oxford, UK: Oxford University Press.

Edwards, A., Housley, W., Williams, M., Sloan, L., \& Williams, M. (2013) Digital social research, social media and the sociological imagination: Surrogacy, augmentation and re-orientation. International Journal of Social Research Methodology, 16(3), 245-260. http://dx.doi.org/10.1080/13645579.2013.774185

Elwood, S., \& Leszczynski, A. (2011). Privacy, reconsidered: New representations, data practices, and the geoweb. Geoforum, 42(1), 6-15. http://dx.doi.org/10.1016/j.geoforum.2010.08.003

Elwood, S., \& Leszczynski, A. (2013). New spatial media, new knowledge politics. Transactions of the Institute of British Geographers, 38(4), 544-559. http://dx.doi.org/10.1111/j.1475-5661.2012.00543.x

Everhart, R. B. (1977). Between stranger and friend: Some consequences of "long term” fieldwork in schools. American Educational Research Journal, 14(1), 1-15. http://dx.doi.org/10.3102/00028312014001001

Fuller, M. (2007). Media ecologies: Materialist energies in art and technoculture. Cambridge, MA: MIT Press.

Gallagher, M. (2009). Ethics. In E. K. M. Tisdall, J. M. Davis, \& M. Gallagher (Eds.), Research with children \& young people (pp. 11-28). London: Sage.

GSMA-Kearney. (2011). African mobile observatory 2011. London: GSMA.

Hargittai, E. (2010). Digital na(t)ives? Variation in Internet skills and uses among members of the "net generation”. Sociological Inquiry, 80(1), 92-113. doi: 10.1111/j.1475-682X.2009.00317.x 
Helsper, E. J., \& Eynon, R. (2009). Digital natives: Where is the evidence? British Educational Research Journal, 36(3), 503-520. doi: 10.1080/01411920902989227

Huhtamo, E., \& Parikka, J. (2011). Media archaeology: Approaches, applications, and implications. Berkeley, CA: University of California Press.

James, C., Davis, K., Flores, A., Francis, J., Pettingill, L., Rundle, M., \& Gardner, H. (2009). Young people, ethics, and the new digital media: A synthesis from the good play project. Cambridge, MA: MIT. Retrieved from http://mitpress.mit.edu/sites/default/files/titles/free_download/9780262513630 _Young_People_Ethics_and_New_Digital_Media.pdf

Jenkins, H. (2006). Convergence culture: Where old and new media collide. New York: New York University Press.

Kim, M. (2008). The creative commons and copyright protection in the digital era: Uses of creative commons licences. Journal of Computer-Mediated Communication, 13, 187-209. http://dx.doi.org/10.1111/j.1083-6101.2007.00392.x

Kitchin, R., \& Dodge, M. (2011). Code/space: Software and everyday life. Cambridge, MA: MIT Press.

Lobe, B., Livingstone, S., Ólafsson, K., \& Simoes, J. A. (2008). Best practice research guide: How to research children and online technologies in comparative perspective (Deliverable D4.2). London: EU Kids Online. Retrieved from http://eprints.lse.ac.uk/21658/

MacQueen, H., Waelde, C., \& Laurie, G. (2007). Contemporary intellectual property. Oxford, UK: Oxford University Press.

Madden, M., Lenhart, A., Cortesi, S., Gasser, U., Duggan, M., Smith, A., \& Beaton, M. (2013). Teens, social media, and privacy (Pew Research Center's Internet \& American life project). Washington, DC: Pew Research Center. Retrieved from http://pewinternet.org/Reports/2013/Teens-Social-Media-AndPrivacy.aspx

Masheroni, G. \& Ólafsson, K. (2013). Mobile internet access and use among European children. Initial findings of the Net Children Go Mobile Project. Milano: Educatt. Retrieved from http://www.netchildrengomobile.eu/wpcontent/plugins/downloads-manager/upload/1stShortReport_webcolori_ultimo.pdf

Meikle, G., \& Young, S. (2012). Media convergence: Networked digital media in everyday life. Basingstoke, UK: Palgrave Macmillan.

Mejias, U. A. (2013). Off the network: Disrupting the digital world. Minneapolis \& London: University of Minnesota Press.

Miskelly, C., Cater, K., Fleuriot, C., Williams, M., \& Wood, L. (2005, May). Locating story: Collaborative community-based located media production. Paper presented at "The Work of Stories", the fourth Media in Transition conference, May 6-8, MIT, Cambridge, MA. Retrieved from http://web.mit.edu/comm-forum/mit4/papers/miskelly.pdf

Ng, A. (2009/10). When users are authors: Authorship in the age of digital media. Vanderbilt Journal of Entertainment and Technology Law, 12(4), 853-888. 
International Journal of Child, Youth, and Family Studies (2014): 5(4.1) 702-717

Ofcom. (2013). Children and parents: Media use and attitudes report. London: Ofcom.

Perkins, C., \& Dodge, M. (2009). Satellite imagery and the spectacle of secret spaces. Geoforum, 40(4), 546-560. http://dx.doi.org/10.1016/j.geoforum.2009.04.012

Plowman, L., \& Stevenson, O. (2012). Using mobile phone diaries to explore children's everyday lives. Childhood, 19(4), 539-553. doi: 10.1177/0907568212440014

Prout, A. (2005). The future of childhood. London: Routledge.

Punch, S. (2003). Childhoods in the majority world: Miniature adults or tribal children? Sociology, 37(2), 277-295. http://dx.doi.org/10.1177/0038038503037002004

Selwyn, N. (2009). The digital native - myth and reality. Aslib Proceedings, 61(4), 364-379. doi: 10.1108/00012530910973776

Slater, D. (2002). Social relationships and identity on-line and off-line. In L. A. Lievrouw \& S. Livingstone (Eds.), Handbook of new media: Social shaping and consequences of ICTs (pp. 533-543), London, UK, Thousand Oaks, USA, \& New Delhi, India: Sage.

Sterne, J. (2012). Mp3: The meaning of a format. Durham, NC: Duke University Press.

Thomas, N. (in press). Children and young people's participation in research. In B. F Duramy \& T. Gal (Eds.), Promoting the participation of children across the globe: From social exclusion to child-inclusive policies. Oxford, UK: Oxford University Press.

Tisdall, E. K. M. (2005). Participation or protection? Children, young people and dissemination. In N. Hallowell, J. Lawton, \& S. Gregory (Eds.), Reflections on research: The realities of doing research in the social sciences (pp. 98-101). Milton Keynes, UK: Open University Press.

Tisdall, E. K. M., Davis, J. M., \& Gallagher, M. (Eds.). (2009). Research with children \& young people. London: Sage. 